statistics are scanty, the shortage of trained staff acute, and where multiple health problems compete for priority. Nevertheless, Dr. Candau is able to report progress in comprehensive health planning in a number of countries, for example, Africa, Latin America, and Asia-the areas presenting the greatest problems.

In campaigns against many of the communicable diseases, the use of rosearch is a valuable adjunct to the work in the field. In its medical research programme, the Organization draws on the advice of leading experts in many special fields and now has the collaboration of laboratories in all parts of the world. The lists of the reference laboratories of the World Hoalth Organization and of scientific meetings during the year provide some indication of the scope of the programme. The research programme is by no means restricted to the communicable diseases. The report contains, for example, accounts of the present studies on cancer (including the possible relation between viruses and cancer), cardiovascular diseases, and human genetics - a new field of activity for the World Health Organization (see Nature, 208, 230; 1965). The importance of immunology is stressed, and achievements are mentioned in the Organization's relatively new programme of immunological research, particularly in relation to parasitic diseases - a hitherto largely unexplored area of immunization in which further research has been planned on the advice of an expert committee.

Other topics dealt with in the "General Review", constituting Part 1, include malaria eradication, environmental health, public health services, health protection and promotion, education and training, biology and pharmacology, health statistics, publications, information, and administration and finance. A final chapter outlines the work done in co-operation with the United Nations and related agencies, and with non-governmental organizations.

Part 2 deals with the health problems and programmes in each of the Organization's six regions-Africa, the Americas, south-east Asia, Europe, eastern Mediterranean and western Pacific. In each chapter, broad surveys of work in the region concerned are complemented by detailed descriptions of some of the typical projects in which the Organization is giving assistance. They include the preparation of a plan to be financed undor the United Nations Special Fund for the metropolitan area of Accra in Ghana; the improvement of nursing education and services in Guatemala; a project in south-east Asia to increase the local production of freeze-dricd smallpox vaccine, which is essential for the successful pursuit of the smallpox eradication campaign in tropical countries; malaria oradication in Pakistan; and, in the western Pacific region, the first regional conference of deans of medical schools. For the European region, one of the projects described is a symposium in Moscow on the toxicology of drugs and methods of ensuring the therapoutic safety of drugs.

The list of current projects contained in Part 3 is a reflexion of the Organization's varied activities and of their adaptation to the particular requirements of countrios in the various regions.

Information given in the annexes includes membership of the Organization, its executive board and expert committees, the budget, the secretariat, fellowships, awards under the medical research programme, and the reference centres.

\title{
A COMPARISON OF EUROPEAN HEALTH SERVICES
}

$\mathrm{A}^{\mathrm{L}}$ LL European countries have some form of administrative arrangements to deal with environmental health; for example, housing standards, water purity, sewage and refuse disposal, and food hygiene. Modern life has brought into prominence new environmental problems, largely arising from industrialization and urbanization. A special monograph on health services in Europe was prepared for the European Conference on Public Health Administration held by the World Health Organization Regional Office for Europe in Zagreb, Yugoslavia, in June 1964*.

Air pollution is one cause for concern. Already most industrialized European countries have special regulations giving local authorities a measure of control over industrial emissions. Czechoslovakia and other countries have established standards for the control of health hazards from this source, while in the Federal Republic of Germany there are trade regulations and a Civil Code. In the U.S.S.R., the Institute of General and Communal Hygiene of the Academy of Medicine is carrying out research on air pollution in the principal industrial centres. Maximum permissible concentrations for 20 pollutants commonly found in the air of industrial cities have already been worked out. In the United Kingdom, smokeless zones are being established under a Clean Air Act. In Spain, provision is made for air disinfection in hospitals and certain clinics, and special legislation has been created covering unhealthy and dangerous gases and smoke.

Noise, as a public health problem, is also being tackled. Bulgaria has imposed restrictions on it in industry and in transport. In Spain, what are called "silence campaigns"

* A limited number of copies of this document (reference Euro 268-4) are available to persons officially or professionally interested in the subject, on request from the World IIealth Organization Regional Office for Europe Copenhagen. have been carried out in the larger towns, where noise elimination is the concern of the municipal authorities and industrial boards. The U.S.S.R. has set up a Central State Health Inspectorate to deal with problems concerned with noise.

In many European countries, in accordance with the requirements of the International Commission on Radiological Protection, radiation hazards have been the subject of precautionary measures. In the United Kingdom, watch is kept on radioactivity in the air and in the soil by the Atomic Energy Authority in collaboration with the Medical and Agricultural Research Councils, and the Ministry of Housing and Local Government supervises the disposal of radioactive material. In Denmark, under an Act which has been in force since 1953, no radioactive material may be manufactured, owned or imported without special permission from the National Health Service, acting on behalf of the Ministry of the Interior; the Act lists safety precautions covering transport, storage, and use. Finland's Radiation Protection Act controls X-ray and other radiation installations, and Norway also has regulations covering the protection of personnel and the transport of radioactive material. Similar provisions exist in Czechoslovakia, Hungary, Ireland, Switzerland and Turkey. In the Federal Republic of Germany, the Max-Planck Institute of Biophysics carries out systematic investigations of radioactivity in ground water, rivers, and soil, and the meteorological stations make regular measurements of radioactivity in the atmosphere.

To-day, all countries in Europe have some arrangements for controlling the spread of infectious diseases, and the incidence of most of them has been on the wane for some time. Tuberculosis, however, still remains a cause for great concern. In the Federal Republic of Germany, several Länder have legislation providing for regular 
chest X-ray examinations. One result of this approach has been the discovery that the percentage of undiagnosed cases of tuberculosis is higher among older people. In Norway, the Ministry of Social Affairs has the power to enforce X-ray sereening of part of, or all, the population, as well as to test for tuberculosis, and to give B.C.G. vaccination. The radiography services in Italy are aimed at detecting not only tubereulosis but also other respiratory diseases, cardiovascular diseases and lung tumours. Compulsory B.C.G. vaccination is practised in some countries, such as Yugoslavia. Tuberculosis is notifiable in most European countries, but not in The Netherlands, Portugal or Romania.

Thero is a good deal of variation in the regulations regarding immunization against such infections as smallpox, diphtheria, tetanus, and whooping cough. Smallpox vaccination is compulsory in most European countries, and it is prescribed by the International Sanitary Regulations. It is required, for example, in Czechoslovakia, Hungary, Turkey, the U.S.S.R., and Yugoslavia, but it is not compulsory in the United Kingdom. In Yugoslavia immunization against diphtheria and tetanus is also obligatory.

Some communicable diseases are confined to particular areas. In Europe, for example, trachoma is endemic only in the Mediterranean countries. Spain carries out trachoma control through a network of clinics helped by the World Health Organization and the United Nations International Children's Emergency Fund; in Greece, treatment and control are carried out through a chain of anti-trachoma dispensaries. In Italy provincial anti-trachoma associations have been set up in co-operation with public and school dispensaries, specialized hospital services, and district health visitor services. Turkey is gaining control over the disease through an increase in the number of dispensaries. Yugoslavia has made a successful attack on its foci of trachoma: senior medical students have carried out surveys among people in affected areas, and suspects are called for examination by specialists. Typhus, formerly widespread in eastern Europe, is now under control, and in Romania success has been achieved through co-operation between Government, the sanitation and epidemiological services, and the public. Public instruction in control methods has boen given by trade unions, co-operative services and the Red Cross organizations.

An important development in the control of communic. able disease has been the recognition of the part that veterinary science can play against zoonoses. In Italy, for example, there is a Veterinary Division within the Ministry of Health, which deals with such diseases as brucollosis, canine rabies and glanders. In Hungary, the sanepids (sanitary and epidemiological stations) have established programmes for brucollosis control in agricultural undertakings, helminthiasis control among school children, and ancylostomiasis control among miners. III Spain close co-operation is maintained betwoen the health authorities and the veterinary services in the control of brucellosis, tuberculosis transmitted by animals, and other zoonoses. Laboratory facilities, an essential element in the control of communicable diseases, are provided by the local sanepids in most eastern European countries, at the health offices in the Federal Republic of Germany and at the universities and hospitals in Austria. In England and Wales there is a national network of laboratories, operated on behalf of the Ministry of Health.

In Yugoslavia, the institutes of hygiene undertake special research projects, as well as routine examinations of public health specimens. This arrangement has been particularly helpful in special field campaigns against endemic syphilis and trachoma.

Other preventive services described in the monograph include food and drug control, matornal and child health, school health, occupational health, mental health and alcoholism, care of the aged, dental care, and health education.

\section{ANTARCTIC AERONOMY AND ICE SHEETS}

$\mathrm{D}$ URING the past ten years the amount of scientific data available from Antaretica has inereased by an order of magnitude. The position has at last been reached when it is stimulating and useful to summarize knowledge in many disciplines in the form of maps. The United States, the U.S.S.R. and the United Kingdom all have projects in hand to publish scientific atlases of Antarctic Research.

The Antarctic Map Folio Series is being published by the American Geographical Society under a contract with the National Science Foundation. The price is most reasonable and indicatos that considerable and welljustified financial support has been given by the National Science Foundation. The form of publication and the contents have been based on replies to lengthy question. naires sent to many interested scientists. The series will consist of about twenty folios, each devoted to one subject or scientific discipline. Each folio consists of a series of maps or diagrams printed on one side of sheets usually $17 \times 22$ in. and several pages of text of $17 \times 11$ in.; some plates are also of this size. Each folio series is contained in a light cardboard folder. Four colours are used in the production of maps.

The first folio* deals with aeronomy and has been produced by members of the AVCO Corporation, Wilmington, Massachusetts. A brief text explains the purpose of the observations and the method of compilation. It also

* American Geographieal Society. Antarctic Map Folio Series. Folio 1: teronomical Maps for the Antarctic. By R. Penndorf, T. M. Noel, G. F. llourke, and M. A. Shea. Pp. $6+9$ plates. (New York: American Geographical Society, 1964.) 3 dollars. includes brief outlines and maps of some data relevint to conjugate points and to the southern auroral zone. The definition of magnetic $B$ and magnotic $L$ values which is given is somewhat involved for the layman. The plates all show ionospheric conditions for 1957 or 1958, the period of maximum sunspot activity. The maps on at scale of about 1 : 100 million show the following parameters: $f_{0} E$ and $f_{0} F_{1}$ at 0000 and 1200 U.T.; $f_{0} F_{2}$ at $3 \mathrm{~h}$ (U.T.) intervals for winter, equinoctial and summer conditions, the percentage of time that $f_{0} E_{s}>5 \mathrm{Mc} / \mathrm{s}$, and magnetic $B$ and $L$ values at $0,100,200,500$, and $1,000 \mathrm{~km}$. The folio should be useful for general reference purposes for scientists in contact with ionospherie problems, but a non-specialist seeking a general appreciation of this work would learn more from a general review article.

The second folio $\dagger$ on the physical characteristics of the Antarctic ice sheet has been compiled in university and other institutes. It deals with several topics of general geographical interest. The Antarctic maps at $1: 13.6$ million are at a scale suitable to the detailed knowledge of many regions. Use of four-colour printing brings out general distributions clearly. Whero both colour shading and data figures are shown, as for net annual accumula. tion of snow and for mean annual temperatures, the effect is good, as one can see cloarly the actual measuroments and the degree of interpolation. However, the surface elevation and ice thickness maps show neither profile

$\dagger$ Folio 2: Physical Characteristics of the Antarctic Ice Sheet. By C. $\mathbf{R}$. Bentley, R. L. Cameron, C. Bull, K. Kojima and A. J. Gow. Pp. $10+1$ plates. (New York: American Geographical Society, 1964.) it dollars. 